\title{
Unraveling the size distributions of surface properties for purple soil and yellow soil
}

\author{
Ying Tang ${ }^{1,2}$, Hang Lî ${ }^{1, *}$, Xinmin Liu ${ }^{1}$, Hualing $\mathrm{Zhu}^{1}$, Rui Tian ${ }^{1}$ \\ 1. Chongqing Key Laboratory of Soil Multi-Scale Interfacial Process, College of Resources and Environment, Southwest University, Chongqing 400715, \\ China.E-mail: ty881012@163.com \\ 2. Research Center for Eco-Environmental Sciences, Chinese Academy of Sciences, Beijing 100085, China
}

\section{A R T I C L E I N F O}

Article history:

Received 17 August 2014

Revised 5 December 2014

Accepted 6 December 2014

Available online 6 April 2015

Keywords:

Particle size distribution

Soil colloids

Surface charge number

Specific surface area

Clay minerals

\begin{abstract}
A B S T R A C T
Soils contain diverse colloidal particles whose properties are pertinent to ecological and human health, whereas few investigations systematically analyze the surface properties of these particles. The objective of this study was to elucidate the surface properties of particles within targeted size ranges (i.e. $>10,1-10,0.5-1,0.2-0.5$ and $<0.2 \mu \mathrm{m}$ ) for a purple soil (Entisol) and a yellow soil (Ultisol) using the combined determination method. The mineralogy of corresponding particle-size fractions was determined by X-ray diffraction. We found that up to $80 \%$ of the specific surface area and $85 \%$ of the surface charge of the entire soil came from colloidal-sized particles $(<1 \mu \mathrm{m})$, and almost half of the specific surface area and surface charge came from the smallest particles $(<0.2 \mu \mathrm{m})$. Vermiculite, illite, montmorillonite and mica dominated in the colloidal-sized particles, of which the smallest particles had the highest proportion of vermiculite and montmorillonite. For a given size fraction, the purple soil had a larger specific surface area, stronger electrostatic field, and higher surface charge than the yellow soil due to differences in mineralogy. Likewise, the differences in surface properties among the various particle-size fractions can also be ascribed to mineralogy. Our results indicated that soil surface properties were essentially determined by the colloidal-sized particles, and the $<0.2 \mu \mathrm{m}$ nanoparticles made the largest contribution to soil properties. The composition of clay minerals within the diverse particle-size fractions could fully explain the size distributions of surface properties. (c) 2015 The Research Center for Eco-Environmental Sciences, Chinese Academy of Sciences.
\end{abstract}

Published by Elsevier B.V.

\section{Introduction}

Particle size distribution is a fundamental soil property that is commonly used to estimate other soil properties and processes, such as water retention characteristics (Guber et al., 2003; Henderson et al., 2005; Wösten et al., 2001), erosion capacity (Cheng et al., 2007; Guo et al., 2007; Wischmeier and Mannering, 1969), and transmission and distribution of nutrients and pollutants (Li and Pang, 2014; Six et al., 2002; Wang and Keller, 2008; Wang et al., 2006). Numerous studies have demonstrated that soil surface properties profoundly influence these soil properties and processes (Bower and Gschwend, 1952; Ding et al., 2010; Fruhstorfer et al., 1993; Jenny and Reitemeier, 1934; Jiang et al., 2011; Li et al., 2010a; Petersen et al., 1996). Of course, the surface properties of soil and the particle size distribution should be interrelated.

Previous studies involving surface properties of soil particles in the sand $(20-2000 \mu \mathrm{m})$, silt $(2-20 \mu \mathrm{m})$ and clay $(<2 \mu \mathrm{m})$ fractions have generally indicated that specific surface area (Dolinar, 2012; Ersahin et al., 2006; Petersen et

\footnotetext{
* Corresponding author. E-mail: lihangswu@163.com (Hang Li).
} 
al., 1996) and surface charge number (Ersahin et al., 2006; Yu, 1976) for a given soil are inversely related to particle size. In contrast to the substantial number of studies that have analyzed the surface properties of larger particles, studies on detailed size distributions of surface properties in the soil clay fraction $(<2 \mu \mathrm{m})$ are rather scarce. Nevertheless, many soil processes are determined by the nature of the clay fraction (Hillel, 1998; Kiem and Kögel-Knabner, 2002; Saggar et al., 1999; Wu et al., 2012; Yonekura et al., 2013). In this size fraction, soil particles within the nanoscale or colloidal range $(<1 \mu \mathrm{m})$ are vital and ubiquitous components in natural systems including soils, water, and atmospheric aerosol (Brunekreef and Russell, 2009; Schmidt, 2010). By virtue of their small size, high surface area and abundant surface defects, colloidal-sized particles are involved in the adsorption, migration and transformation of chemical contaminants, heavy metals, and nutrients (Grolimund et al., 1996; McCarthy and Zachara, 1989; Ryan and Elimelech, 1996; Wilkinson and Lead, 2007), which are key factors in several environmental problems (e.g., soil erosion, water eutrophication, heavy metal pollution and air pollution). Moreover, ingestion of fine-sized soil particles associated with many trace metals (Ajmone-Marsan et al., 2008; Madrid et al., 2008) and organic contaminants (Luo et al., 2011) through the water or air can even pose special risks to human health. Therefore, there is an increasing interest in extraction and characterization of colloidal-sized particles, especially natural nanoparticles in soils (Bakshi et al., 2014; Calabi-Floody et al., 2011; Li et al., 2010b; Li et al., 2012; Tian et al., 2014). For example, Calabi-Floody et al. (2011) extracted nanomaterials from the clay fraction of an Andisol and compared the zeta potential of these particles. However, little information on the systematic characterization of surface properties and mineralogy of soil colloidal particles in different size ranges was reported. Clearly, this information can provide insight into the interactions of colloidal-sized particles with environmental pollutants and ultimately clarify the role of colloidal particles in environmental problems.

Soils are composed of abundant clay minerals with constant-charge surfaces. Each kind of clay mineral has specific surface properties, and expansive clay minerals seem to have a dominant influence on soil properties due to their high specific surface area and surface reactivity. Given that the contents and proportions of mineralogical constituents are different in various soil fractions (Huang, 2000; Tsao et al., 2013), the mineral composition should be an important influence factor of the size distributions of soil surface properties. Nevertheless, the lack of the accurate determinations of different surface properties for soil particles within a targeted size range under the same experimental conditions handicaps the valid evaluation of their relationship with soil mineralogy, and ultimately hinders the quantitative assessment of their role in reactions and processes in soils. Fortunately, the combined determination method (Li et al., 2011) in this paper compensates for this shortage.

In this article, special attention was directed to yellow soil and purple soil, which are widespread in southwestern China. We systematically measured the surface properties and mineralogy of soil particles in different size ranges (i.e., $>10$, $1-10,0.5-1,0.2-0.5$ and $<0.2 \mu \mathrm{m}$ ) for these soils, with the aims
(1) to clarify the size distributions of surface properties for different kinds of soils, (2) to identify the composition of clay minerals in various particle-size fractions, and (3) to elucidate the relationship between surface properties and soil mineralogy in the size distribution.

\section{Materials and methods}

\subsection{Separation and collection of soil particles within different size ranges for the tested soils}

The yellow soil (Ultisol) and purple soil (Entisol) were collected from Chongqing, Southwestern China $\left(29^{\circ} 45^{\prime} \mathrm{N}, 106^{\circ} 19^{\prime} \mathrm{E}\right)$. Soil samples were taken from a depth of $0-20 \mathrm{~cm}$ within the profile, air dried at room temperature, gently crumbled and passed through a $2 \mathrm{~mm}$ mesh sieve to remove plant roots, stones and other large substances. A portion of each soil sample was used for basic chemical property analysis. The $\mathrm{pH}$ of the bulk soil suspension was measured at a soil/solution ratio of 1:2.5 in both ultrapure water and $1.0 \mathrm{~mol} / \mathrm{L} \mathrm{KCl}$ solution using a $\mathrm{pH}$ electrode. The organic matter content was measured by the potassium dichromate oxidation method (Yang et al., 2008). The cation exchange capacity was measured with the exchange method (Hu et al., 2000), and the free Fe oxide was determined by the citrate-bicarbonate-dithionite method (Lu, 2000). All the selected chemical properties of the bulk soils are displayed in Table 1.

Another portion of each soil sample was prepared for subsequent extraction of particles in different size fractions. Soil particles in size fractions of $>10,1-10,0.5-1,0.2-0.5$ and $<0.2 \mu \mathrm{m}$ were subsequently isolated according to the following procedure. First, air-dried soil particles for the purple soil and yellow soil were treated with $30 \%$ hydrogen peroxide $\left(\mathrm{H}_{2} \mathrm{O}_{2}\right)$ to remove the associated organic matter (Calabi-Floody et al., 2011; House and Farr, 1989). The procedure involved ultrasonically dispersing the particles in ultrapure water, adding an appropriate amount of $\mathrm{H}_{2} \mathrm{O}_{2}$ solution to the suspension, heating at $60^{\circ} \mathrm{C}$ for $16 \mathrm{hr}$ with intensive stirring, and washing away the excess $\mathrm{H}_{2} \mathrm{O}_{2}$ with ultrapure water. Then the obtained soil suspension was oven-dried at $75^{\circ} \mathrm{C}$ and passed through a $<0.25 \mathrm{~mm}$ mesh sieve. Second, $50.0 \mathrm{~g}$ of the obtained soil particles was treated with $0.01 \mathrm{~mol} / \mathrm{L} \mathrm{KOH}$ solution in $500 \mathrm{~mL}$ of ultrapure water to adjust the $\mathrm{pH}$ value to 7.5. The suspension was then ultrasonically dispersed at a frequency of $20 \mathrm{kHz}$ for $30 \mathrm{~min}$ by a probe-type ultrasonic homogenizer (Scientz-IID,Ningbo Scientz Biotechnology Co., Ltd., Zhejiang, China), before diluting to $5000 \mathrm{~mL}$ with ultrapure water. Finally, soil particles $<10 \mu \mathrm{m}$ were extracted

Table 1 - Basic chemical properties of two tested soils.

\begin{tabular}{lcccc}
$\begin{array}{c}\text { Soil } \\
\text { types }\end{array}$ & pH & $\begin{array}{c}\text { Organic matter } \\
\text { content } \\
(\mathrm{g} / \mathrm{kg})\end{array}$ & $\begin{array}{c}\mathrm{CEC} \\
\left(\mathrm{cmol}_{(-)} / \mathrm{kg}\right)\end{array}$ & $\begin{array}{c}\text { Free iron } \\
\text { oxides } \\
(\mathrm{g} / \mathrm{kg})\end{array}$ \\
\hline Purple soil & 7.1 & 18.5 & 32.0 & 4.21 \\
Yellow soil & 4.4 & 2.85 & 11.9 & 10.4 \\
\hline \multicolumn{7}{l}{ CEC: cation exchange capacity. } \\
\hline
\end{tabular}


and collected by sedimentation under gravity, according to Stokes' Law (Jia et al., 2013; Li et al., 2010b; Tian et al., 2013; Tsao et al., 2013; Xiong et al., 1985), and the residue (>10 $\mu \mathrm{m})$ was weighed after drying to a constant weight in an oven at $75^{\circ} \mathrm{C}$. The particles in the $<10 \mu \mathrm{m}$ size fraction were then treated as the original material to successively extract the particles in size fractions of $<1,<0.5$ and $<0.2 \mu \mathrm{m}$ by the same treatment mentioned above. To validate the method for extraction of fine clay particles, the size (hydrodynamic) distribution of the extracted $<0.2 \mu \mathrm{m}$ soil particles for both purple soil and yellow soil was measured with the dynamic light scattering technique as shown in Fig. 1. It was found that in fact the extracted particles were mainly distributed in the range of $<200-250 \mathrm{~nm}$ in diameter. Thus our extraction method was valid. Table 2 provides the percentages of particles with different size fractions (i.e., >10, 1-10, 0.5-1, $0.2-0.5$ and $<0.2 \mu \mathrm{m}$ ) by weight.

\subsection{Surface properties and soil mineralogy analyses}

Surface properties of soil particles within a targeted size range were measured using the combined determination method ( $\mathrm{Li}$ et al., 2011). First, H-saturated samples were prepared by washing the soil particles several times with a $0.1 \mathrm{~mol} / \mathrm{L} \mathrm{HCl}$ solution and then with ultrapure water repeatedly until the solution was free of $\mathrm{Cl}^{-}$in suspension. Second, about $5.0 \mathrm{~g}$ of the oven-dried $\mathrm{H}$-saturated sample was added successively with an equal volume (depending on the surface charges of the sample) of $0.02 \mathrm{~mol} / \mathrm{L} \mathrm{Ca}(\mathrm{OH})_{2}$ solution and $\mathrm{NaOH}$ solution into a $150 \mathrm{~mL}$ triangular bottle. Several drops of $0.1 \mathrm{~mol} / \mathrm{L} \mathrm{HCl}$ solution were used to adjust the $\mathrm{pH}$ of the suspension to 7.0 after intensive shaking for $24 \mathrm{hr}$. The suspension was centrifuged and the supernatant was collected after another $24 \mathrm{hr}$ of shaking. Third, the final $\mathrm{pH}$ and the activities of $\mathrm{Na}^{+}$ $\left(a^{0}{ }_{\mathrm{Na}}\right)$ and $\mathrm{Ca}^{2+}\left(a^{0} \mathrm{Ca}\right)$ in bulk solution were measured by $\mathrm{H}$-ion, $\mathrm{Na}$-ion and Ca-ion selective electrodes, respectively. Then the absorbed quantities of $\mathrm{Na}^{+}\left(\mathrm{N}_{\mathrm{Na}}\right)$ and $\mathrm{Ca}^{2+}\left(\mathrm{N}_{\mathrm{Ca}}\right)$ (i.e., differences between the added and remaining quantities of $\mathrm{Na}^{+}$and
Table 2 - Particle size distribution of the two soils.

\begin{tabular}{lccccc} 
Materials & \multicolumn{5}{c}{ Particle size $(\mu \mathrm{m})$} \\
\cline { 2 - 6 } & $>10$ & $1-10$ & $0.5-1$ & $0.2-0.5$ & $<0.2$ \\
\hline Purple soil & $36.3 \%$ & $27.4 \%$ & $14.1 \%$ & $5.44 \%$ & $16.8 \%$ \\
Yellow soil & $34.9 \%$ & $28.8 \%$ & $6.10 \%$ & $9.86 \%$ & $20.3 \%$ \\
\hline
\end{tabular}

$\mathrm{Ca}^{2+}$ ) on charged particle surfaces were measured. By introducing the experimental data into the following Eqs. (1)-(5) (Li et al., 2011; Liu et al., 2010), the specific surface area, surface charge, surface potential, and electrostatic field strength at the surface for different particle size fractions of the soils were calculated.

$$
\begin{aligned}
& \varphi_{0}=-2 R T /\left(2 \beta_{\mathrm{Ca}}-\beta_{\mathrm{Na}}\right) / F \times \ln \left[\left(a_{\mathrm{Ca}}^{0} N_{\mathrm{Na}}\right) /\left(a_{\mathrm{Na}}^{0} N_{\mathrm{Ca}}\right)\right] \\
& \sigma=\operatorname{sgn}(\varphi) \sqrt{\frac{\varepsilon R T}{2 \pi}}\left[a_{\mathrm{Na}}^{0}\left(\mathrm{e}^{\frac{\beta_{\mathrm{Na}} F \varphi}{R T}}-1\right)+a_{\mathrm{Ca}}^{0}\left(\mathrm{e}^{\frac{2 \beta_{\mathrm{a}} F \varphi}{R T}}-1\right)+\left(a_{\mathrm{Na}}^{0}+2 a_{\mathrm{Ca}}^{0}\right)\left(\mathrm{e}^{\frac{F \varphi}{R T}}-1\right)\right]
\end{aligned}
$$

$E=4 \pi \sigma / \varepsilon$

$S=\frac{N_{\mathrm{Na}} \kappa}{m a_{\mathrm{Na}}^{0}} \mathrm{e}^{\frac{\beta_{\mathrm{Na}} \mathrm{F}_{\varphi}}{2 R T}}=\frac{N_{\mathrm{Ca}} \kappa}{m a_{\mathrm{Ca}}^{0}} \mathrm{e}^{\frac{2 \beta_{\mathrm{Ca}} \mathrm{F}_{\varphi}}{R I}}$

$S C N=10^{5} S \sigma / F$

where

$\beta_{\mathrm{Ca}}=-0.0213 \ln \left(I^{0.5}\right)+1.2331$

$\beta_{\mathrm{Na}}=0.0213 \ln \left(\mathrm{I}^{0.5}\right)+0.7669$

$m=0.5259 \ln \left(c_{\mathrm{Na}}^{0} / c_{\mathrm{ca}}^{0}\right)+1.992$

where, $\varphi_{0}(\mathrm{~V})$ is the surface potential; $\sigma\left(\mathrm{C} / \mathrm{dm}^{2}\right)$ is the surface charge density; $E(\mathrm{~V} / \mathrm{dm})$ is the electrostatic field strength at surface; $\mathrm{S}\left(\mathrm{dm}^{2} / \mathrm{kg}\right)$ is the specific surface area; SCN $(\mathrm{mol} / \mathrm{kg})$ is the surface charge number; $R(\mathrm{~J} /(\mathrm{K} \cdot \mathrm{mol}))$ is the universal gas constant; $\mathrm{T}(\mathrm{K})$ is the absolute temperature; $\mathrm{F}(\mathrm{C} / \mathrm{mol})$ is the
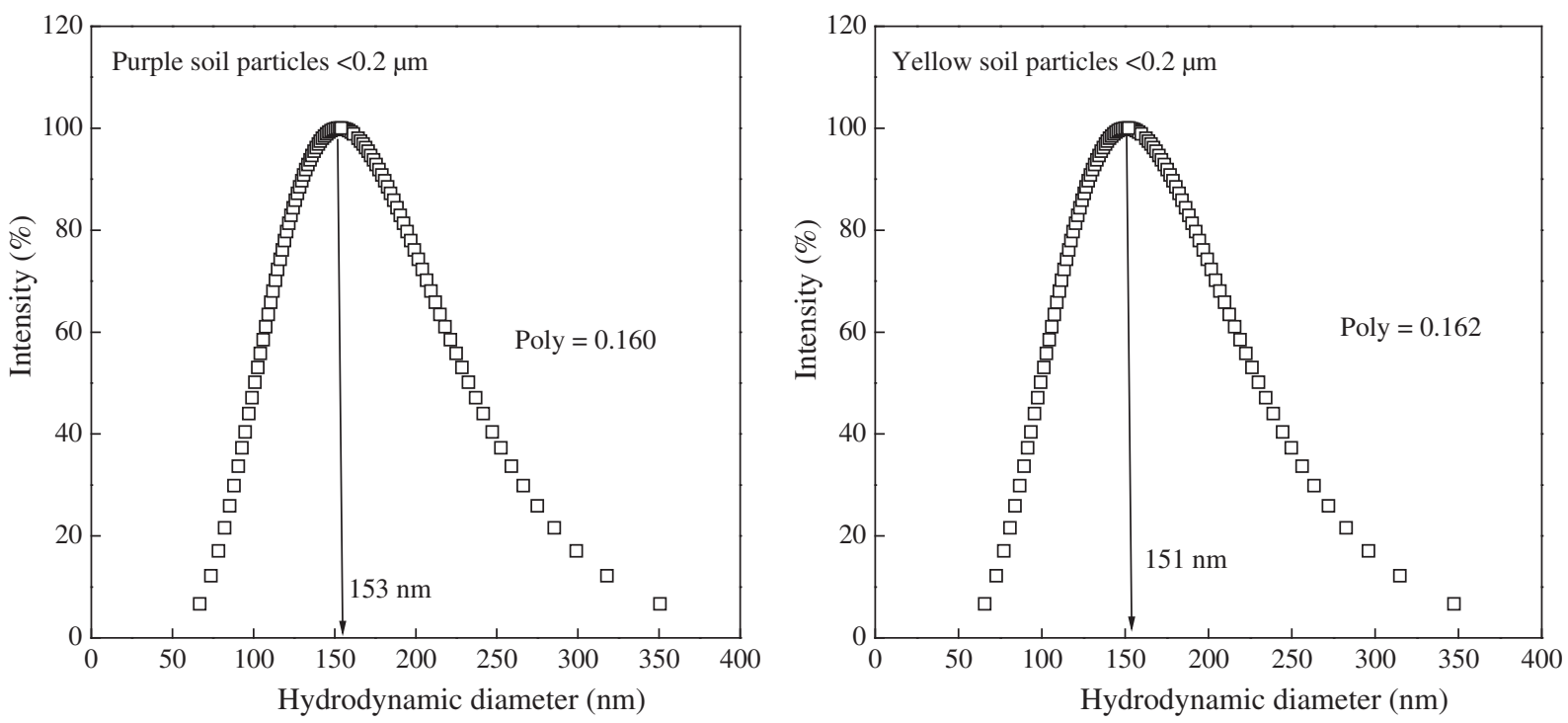

Fig. 1 - Particle size distribution of soil particles in the $<0.2 \mu \mathrm{m}$ size fraction. 
Faraday constant; $Z$ is the charge of each ion species; $\beta_{\mathrm{Na}}$ and $\beta_{\mathrm{Ca}}$ are the corresponding modification factor of $\mathrm{Z}$ for $\mathrm{Na}^{+}$and $\mathrm{Ca}^{2+}$, respectively; $\kappa(1 / \mathrm{dm})$ is the Debye-Huckel parameter; $\varepsilon$ is the dielectric constant $\left(8.9 \times 10^{-10} \mathrm{C}^{2} /(\mathrm{J} \cdot \mathrm{dm})\right.$ for water $) ; \mathrm{I}(\mathrm{mol} / \mathrm{L})$ is the ionic strength, $c^{0} \mathrm{Na}(\mathrm{mol} / \mathrm{L})$ and $c^{0}{ }_{\mathrm{Ca}}(\mathrm{mol} / \mathrm{L})$ is equilibrium concentration of $\mathrm{Na}^{+}$and $\mathrm{Ca}^{2+}$ in bulk solution, respectively.

$\mathrm{X}$-ray diffraction (XRD) analysis was conducted to determine soil mineralogy, especially for the clay mineral types (Tsao et al., 2013; Wang et al., 2006). The soil clay mineral compositions of the samples studied were detected and analyzed by the Bioelements Analysis Laboratory (College of Resources and Environment, Southwest University) with an $\mathrm{X}$-ray diffractometer (XD-3, Beijing Purkinje General Instrument Co., Ltd., Beijing, China).

\section{Results and discussion}

\subsection{Mineralogy of the clay minerals of the various particle-size fractions}

The results of the semi-quantitative analysis of clay minerals for soil particles in different size fractions are displayed in Table 3. On one hand, the contents and proportions of minerals were different in the different soils. Quartz, mica, kaolinite, illite and vermiculite were found to exist in soil particles for both purple soil and yellow soil, whereas montmorillonite and albite were only detected in purple soil particles. Additionally, for a targeted size range, the purple soil particles contained more abundant expansive clay minerals (i.e., vermiculite and montmorillonite) as compared with the yellow soil particles. On the other hand, prominent differences of mineralogical constituents were observed in soil particles for different size fractions. Specifically, the larger purple soil particles of the size range $>1 \mu \mathrm{m}$ had abundant soil primary minerals (albite and quartz), while the colloidal-sized particles contained more secondary clay minerals, which have higher surface charge and larger specific surface area. The composition of the secondary clay minerals varied remarkably among the $0.5-1,0.2-0.5$ and $<0.2 \mu \mathrm{m}$ size fractions in purple soil particles. In particular, for fractions in the smallest particle-size range $(<0.2 \mu \mathrm{m})$, over half of the clay minerals were expansive clay minerals. Similarly, for the yellow soil, plenty of quartz particles were present in the $>10 \mu \mathrm{m}$ and $1-10 \mu \mathrm{m}$ size fractions. In the colloidal-sized particles, vermiculite and illite gradually increased in relative abundance as the particle size range decreased from $0.5-1 \mu \mathrm{m}$ to $<0.2 \mu \mathrm{m}$. Our results are consistent with the observations of Tsao et al. (2013). In their study, the content of soil primary minerals (i.e., quartz) decreased with decreasing particle size, while the content of secondary clay minerals (i.e., kaolinite) rapidly increased with the decline of particle size.

Note that expansive clay minerals have larger specific surface area and higher surface charge, and that montmorillonite has the largest specific surface area and highest surface charge, so the differences in mineralogical compositions among particles and soils should lead to differences in their surface properties, as will be confirmed in the discussion below.

\subsection{Surface properties and interaction forces of the various particle-size fractions}

\subsubsection{Surface properties}

For both variably and permanently charged soil, under a given $\mathrm{pH}$ condition, the surface properties were independent of solution composition and concentration, except for surface potential (Li et al., 2011). In our experiments, the $\mathrm{pH}$ conditions were approximately constant, thus the corresponding surface properties of particles in different size fractions are shown in Table 4.

Table 4 shows that the size distribution of surface properties for the two soils was perfectly consistent with the changing trends of mineralogical components among particles and soils. Smaller purple soil particles were observed to have larger specific surface area. Briefly, specific surface area dramatically increased from $2.76 \times 10^{3} \mathrm{dm}^{2} / g$ to $42.1 \times 10^{3} \mathrm{dm}^{2} /$ gas particle size decreased from $>10 \mu \mathrm{m}$ to $<0.2 \mu \mathrm{m}$. Likewise, the yellow soil exhibited a distinct increase in specific surface area with the decline in particle size, except for particles in the 1-10 $\mu \mathrm{m}$ and $0.2-0.5 \mu \mathrm{m}$ size fractions. Although colloidal-sized particles in the size range $<1 \mu \mathrm{m}$ exhibited a specific surface area one order of magnitude larger than that of the particles in the size range $>1 \mu \mathrm{m}$ for both soils, the specific surface area of colloidal-sized particles for the purple soil was larger than that for the yellow soil.

The charge on the surface of particles for the two soils increased significantly with decreasing particle size, such that the surface charge of particles in the smallest size range $(<0.2 \mu \mathrm{m})$ was two orders of magnitude higher than that in the

Table 3 - Semi-quantitative analysis of clay compositions in various particle-size fractions for the two soils.

\begin{tabular}{|c|c|c|c|c|c|c|c|c|}
\hline Materials & Particle size $(\mu \mathrm{m})$ & Quartz & Mica & Kaolinite & Illite & Montmorillonite & Vermiculite & Albite \\
\hline \multirow[t]{5}{*}{ Purple soil } & $>10$ & +++ & ++ & - & + & - & + & +++ \\
\hline & $1-10$ & +++ & +++ & - & + & - & + & ++ \\
\hline & $0.5-1$ & ++ & +++ & + & ++ & - & ++ & + \\
\hline & $0.2-0.5$ & ++ & +++ & + & +++ & - & - & + \\
\hline & $<0.2$ & + & ++ & - & ++ & ++ & +++ & + \\
\hline \multirow[t]{5}{*}{ Yellow soil } & $>10$ & +++++ & + & - & - & - & - & - \\
\hline & $1-10$ & ++++ & ++ & - & + & - & - & - \\
\hline & $0.5-1$ & - & ++++ & + & ++ & - & + & - \\
\hline & $0.2-0.5$ & + & +++ & + & +++ & - & ++ & - \\
\hline & $<0.2$ & + & ++ & + & +++ & - & ++ & - \\
\hline
\end{tabular}

Symbols of -: trace or not detected; +: <10\%; ++: 10\%-25\%; +++: $25 \%-50 \% ;++++: 50 \%-75 \% ;+++++:>75 \%$. 


\section{Table 4 - Surface properties of the original soil and particles within different size ranges.}

\begin{tabular}{llccccc} 
Materials & $\begin{array}{c}\text { Particle } \\
\text { size } \\
(\mu \mathrm{m})\end{array}$ & $\mathrm{pH}$ & $\begin{array}{c}\text { Specific surface } \\
\text { area } \\
\left(10^{3} \mathrm{dm}^{2} / \mathrm{g}\right)\end{array}$ & $\begin{array}{c}\text { Surface charge } \\
\text { density } \\
\left(10^{-3} \mathrm{C} / \mathrm{dm}^{2}\right)\end{array}$ & $\begin{array}{c}\text { Surface charge } \\
\text { number } \\
\left(\mathrm{cmol}_{(-)} / \mathrm{kg}\right)\end{array}$ & $\begin{array}{c}\text { Electrostatic field strength at } \\
\text { surface } \\
\left(10^{8} \mathrm{~V} / \mathrm{m}\right)\end{array}$ \\
\hline Purple soil & $>10$ & 6.94 & $2.76 \pm 0.06 \mathrm{a}$ & $3.05 \pm 0.49 \mathrm{a}$ & $9.96 \pm 0.57 \mathrm{a}$ & $4.30 \pm 0.69 \mathrm{a}$ \\
& $1-10$ & 6.78 & $3.31 \pm 0.01 \mathrm{a}$ & $5.56 \pm 0.35 \mathrm{~b}$ & $19.6 \pm 0.8 \mathrm{~b}$ & $7.85 \pm 0.50 \mathrm{~b}$ \\
& $0.5-1$ & 7.23 & $16.3 \pm 0.2 \mathrm{~b}$ & $2.81 \pm 0.11 \mathrm{a}$ & $47.3 \pm 1.1 \mathrm{c}$ & $3.96 \pm 0.16 \mathrm{a}$ \\
& $0.2-0.5$ & 7.32 & $19.9 \pm 0.1 \mathrm{~b}$ & $3.77 \pm 0.01 \mathrm{a}$ & $77.6 \pm 0.4 \mathrm{~d}$ & $3.32 \pm 0.01 \mathrm{a}$ \\
Yellow & $<0.2$ & 7.25 & $42.1 \pm 0.1 \mathrm{c}$ & $2.42 \pm 0.19 \mathrm{a}$ & $104 \pm 1 \mathrm{e}$ & $0.27 \mathrm{a}$ \\
soil & 10 & 7.27 & $7.05 \pm 0.01 \mathrm{~b}$ & $0.0944 \pm 0.001 \mathrm{a}$ & $0.693 \pm 0.060 \mathrm{a}$ & $0.133 \pm 0.009 \mathrm{a}$ \\
& $1-10$ & 7.17 & $4.07 \pm 0.01 \mathrm{a}$ & $0.634 \pm 0.026 \mathrm{~b}$ & $2.68 \pm 0.09 \mathrm{~b}$ & $0.016 \mathrm{~b}$ \\
& $0.5-1$ & 7.13 & $17.3 \pm 0.2 \mathrm{~d}$ & $0.609 \pm 0.014 \mathrm{~b}$ & $10.8 \pm 0.2 \mathrm{c}$ & $0.844 \pm 0.011 \mathrm{~b}$ \\
& $0.2-0.5$ & 7.05 & $12.7 \pm 0.1 \mathrm{c}$ & $1.13 \pm 0.31 \mathrm{c}$ & $14.4 \pm 1.2 \mathrm{~d}$ & $1.60 \pm 0.43 \mathrm{c}$ \\
& $<0.2$ & 7.00 & $18.5 \pm 0.6 \mathrm{~d}$ & $1.42 \pm 0.09 \mathrm{c}$ & $27.2 \pm 1.4 \mathrm{e}$ & $2.00 \pm 0.13 \mathrm{c}$
\end{tabular}

Data are means \pm standard deviation of three replicates; significant differences between treatments at $p<0.05$ are indicated with different letters.

largest size range $(>10 \mu \mathrm{m})$. Moreover, for a given particle-size fraction, the surface charges in the purple soil were much higher than in the yellow soil. For example, the surface charge in the $>10 \mu \mathrm{m}$ size fraction for the purple soil $\left(9.96 \mathrm{cmol}_{(-)} / \mathrm{kg}\right)$ was 14 times higher than that in the yellow soil $\left(0.693 \mathrm{cmol}_{(-)} / \mathrm{kg}\right)$.

The yellow soil and purple soil particles exhibited completely different trends in the size distributions of surface charge density and electrostatic field strength at the surface. The purple soil particles in the size range $1-10 \mu \mathrm{m}$ held the highest surface charge density $\left(5.56 \times 10^{-3} \mathrm{C} / \mathrm{dm}^{2}\right)$ and the strongest electrostatic field at the surface $\left(7.85 \times 10^{8} \mathrm{~V} / \mathrm{m}\right)$, while no significant differences of these two properties were detected among particles within other size ranges. Unlike the purple soil, the surface charge density and electrostatic field strength at the surface for the yellow soil increased significantly with decreasing particle size, and the two properties in the $<0.2 \mu \mathrm{m}$ size fraction was fifteen times higher than in the $>10 \mu \mathrm{m}$ size fraction.

Furthermore, the contributions of an individual particlesize fraction to the specific surface area and surface charge number of the entire soil can be calculated using Eqs. (6) and (7) and the results are displayed in Table 5:

$\alpha_{i S}=\frac{\left(r_{i} \times S_{i}\right)}{\sum r_{i} \times S_{i}} \times 100 \%$

$\alpha_{i S C N}=\frac{\left(r_{i} \times S C N_{i}\right)}{\sum r_{i} \times S C N_{i}} \times 100 \%$

where, $\alpha_{i s}$ and $\alpha_{i S C N}$ are the contribution rates of an individual particle-size fraction (i) to the overall specific surface area and surface charge, respectively, which has limits of $0-100 \%$; $r_{i}$ is the weight percentage of particles in this particle-size fraction (Table 2); $\mathrm{S}_{\mathrm{i}}\left(\mathrm{dm}^{2} / \mathrm{g}\right)$ and $\mathrm{SCN}_{\mathrm{i}}\left(\mathrm{cmol}_{(-)} / \mathrm{kg}\right)$ are the specific surface area and surface charge of particles in this particlesize fraction (Table 4).

Clearly, more than $80 \%$ and $60 \%$ of specific surface area as well as $75 \%$ and $85 \%$ of surface charge came from the colloidal-sized particles of the size range $<1 \mu \mathrm{m}$ for the two soils, respectively, indicating that surface properties of the entire soil were essentially determined by the nature of the colloidal-sized particles, even though the mass of these particles can be merely a few percent of the total (Table 2).
Furthermore, although fractions in the smallest particle-size range $<0.2 \mu \mathrm{m}$ only comprised less than one fifth of the bulk soil, approximately half of the specific surface area and surface charge of the entire soil came from these particles, indicating that the smallest particles played an extremely crucial role in the overall soil properties.

Based on the specific surface area (S) and surface charge number (SCN) of soil particles within different size ranges calculated above (Table 4), under a given concentration of a single 1:1 or 2:1 electrolyte solution, the surface potential of those soil particles can be calculated with Eqs. (8) and (9), respectively (Li et al., 2011):

\section{1:1 Electrolyte solution:}

$$
\varphi_{0}=-2 R T /(Z F) \times \ln \left(2 a^{0} / \widetilde{c}\right)
$$

2:1 Electrolyte solution:

$$
\varphi_{0}=-2 R T /(Z F) \times \ln \left(\sqrt{3} a^{0} / \widetilde{c}\right)
$$

where:

$$
\widetilde{c}=S C N \times \kappa / S
$$

and

$$
\kappa=\sqrt{8 \pi F^{2}\left(\frac{1}{2} \times \sum a^{0} Z^{2}\right) /(\varepsilon R T)}
$$

where, $\widetilde{c}(\mathrm{~mol} / \mathrm{L})$ is the average concentration of any given cation species in the diffuse layer, and $a^{0}(\mathrm{~mol} / \mathrm{L})$ is the

Table 5-Contribution rates of the various particle-size fractions to the specific surface area and surface charges.

\begin{tabular}{lcccc} 
Particle size & Specific surface area & \multicolumn{2}{c}{$\begin{array}{c}\text { Surface charge } \\
\text { number }\end{array}$} \\
\hline$(\mu \mathrm{m})$ & Purple soil & Yellow soil & Purple soil & Yellow soil \\
$>10$ & $8.13 \%$ & $25.3 \%$ & $9.68 \%$ & $2.80 \%$ \\
$1-10$ & $7.35 \%$ & $12.1 \%$ & $14.4 \%$ & $8.96 \%$ \\
$0.5-1$ & $18.6 \%$ & $10.9 \%$ & $17.9 \%$ & $7.64 \%$ \\
$0.2-0.5$ & $8.75 \%$ & $12.8 \%$ & $11.3 \%$ & $16.4 \%$ \\
$<0.2$ & $57.2 \%$ & $38.9 \%$ & $46.8 \%$ & $64.2 \%$ \\
\hline
\end{tabular}


equilibrium concentration of this cation species in bulk solution, which is defined as $0-1 \mathrm{~mol} / \mathrm{L}$ in this study.

A significant negative logarithmic trend was evident for surface potential with increasing electrolyte concentrations for the two soils (Fig. 2). The surface potential of soil particles in a 1:1 electrolyte solution exceeded that in a 2:1 electrolyte solution under the same electrolyte concentration and particle-size fraction conditions. At any given electrolyte concentration, great differences of surface potential were found among various particle-size fractions, and the purple soil and yellow soil had almost reversed variation trends in the size distribution of surface potential. For instance, in the $0.01 \mathrm{~mol} / \mathrm{L} 1: 1$ electrolyte solution, the surface potential in the $>10,1-10,0.5-1,0.2-0.5$ and $<0.2 \mu \mathrm{m}$ size fractions for the purple soil particles were $-0.209,-0.235,-0.198,-0.213$ and $-0.190 \mathrm{~V}$, respectively. Thus the sequence was $\varphi_{0}(1-10 \mu \mathrm{m})>\varphi_{0}(0.2-$ $0.5 \mu \mathrm{m})>\varphi_{0}(>10 \mu \mathrm{m})>\varphi_{0}(0.5-1 \mu \mathrm{m})>\varphi_{0}(<0.2 \mu \mathrm{m})$ for the purple soil. However, the corresponding surface potentials of particles within the targeted size ranges for the yellow soil were $-0.0242,-0.122,-0.119,-0.150$ and $-0.163 \mathrm{~V}$, respectively, and the sequence therefore was $\varphi_{0}(<0.2 \mu \mathrm{m})>\varphi_{0}(0.2-0.5 \mu \mathrm{m})>\varphi_{0}$ $(1-10 \mu \mathrm{m})>\varphi_{0}(0.5-1 \mu \mathrm{m})>\varphi_{0}(>10 \mu \mathrm{m})$ for the yellow soil. Combining Eqs. (3) and (4), we can see the differences of surface potential of particles in different size fractions stem from their surface charge density, and the sequence of surface charge density (Table 4) was in good agreement with that of the surface potential for the two soils.
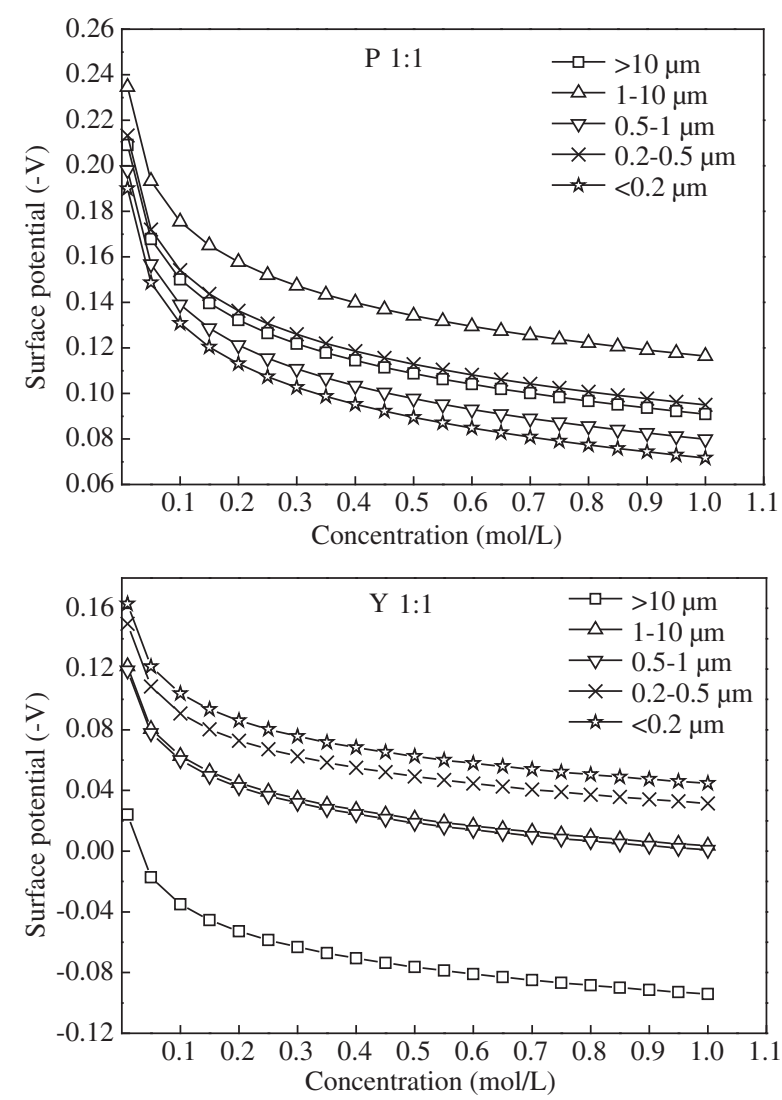

2.2.2. Assessment of electrostatic repulsive pressure between adjacent particles

After quantitatively characterizing the surface properties of particles in various size fractions, it was possible to evaluate the interactions among particles within a targeted size range. For example, the electrostatic repulsive pressure between adjacent soil particles in a single 1:1 or 2:1 electrolyte solution can be calculated (Ducker et al., 1992) as:

$P_{\mathrm{EDL}}(d)=2 / 101 \times R T a^{0}\{\cosh [Z F \varphi(d / 2) /(R T)]-1\}$

where $P_{\mathrm{EDL}}(d)(\mathrm{atm})$ is the electrostatic repulsive pressure and $d$ is the distance between two adjacent particle surfaces. The potential at the mid-point of the two adjacent particle surfaces $(\varphi(d / 2))$ can also be calculated (Hou et al., 2009; Li et al., 2009) as:

$\frac{\pi}{2}\left[1+\left(\frac{1}{2}\right)^{2} e^{\frac{2 Z F \varphi\left(\frac{d}{2}\right)}{R T}}+\left(\frac{3}{8}\right)^{2} e^{\frac{4 Z F \varphi\left(\frac{d}{2}\right)}{R T}}\right]-\operatorname{arcsine} e^{\frac{Z \varphi_{0}-Z F \varphi\left(\frac{d}{2}\right)}{2 R T}}=1 / 4 \times d \kappa e^{-\frac{Z F_{\varphi}\left(\frac{d}{2}\right)}{2 R T}}$.

For electrolyte concentration $0.01 \mathrm{~mol} / \mathrm{L}$, the surface potential $\left(\varphi_{0}\right)$ of particles in a given size fraction is calculated by Eqs. (8) and (9). Integrating Eqs. (10) and (11), the electrostatic repulsive pressure of soil particles for different distances between two adjacent particle surfaces was calculated (Fig. 3).

The analysis of electrostatic repulsive pressure in Fig. 3 shows a significant negative logarithmic decrease with increasing
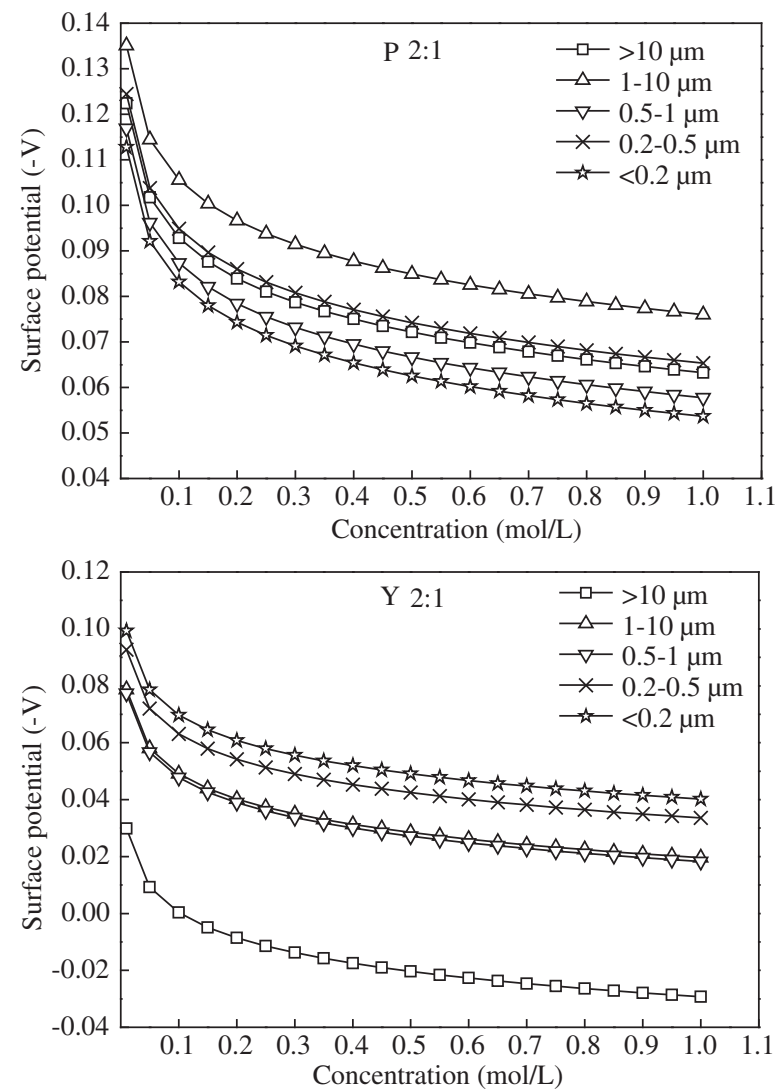

Fig. 2 - Surface potential of soil particles within different size ranges under different concentrations of a single 1:1 or 2:1 electrolyte solution. P: purple soil, Y: yellow soil. 
distance between two adjacent particle surfaces. The difference of electrostatic repulsive pressure between soil particles in different size fractions became more significant at smaller distances from the particle surface. Generally, smaller soil particles had stronger electrostatic repulsive pressure between adjacent particles for the two soils when the other conditions were the same. In addition, under the same size fraction and electrolyte composition conditions, the electrostatic repulsive pressure between the purple soil particles was very much higher than that between the yellow soil particles.

The above discussion showed that, the high charge densities for different particle-size fractions could produce a strong electric field around particles, and this electric field would further produce strong electrostatic repulsive pressure between adjacent particles in soil aggregates, which would result in soil aggregate breakdown, making small clay particles easier to disperse in water to form a suspension. Finally, through the flow of the suspension, fine soil particles along with adsorbed nutrients and contaminants would flow into other natural systems.

$\mathrm{Hu}$ et al. (2015) have quantitatively analyzed how the electrostatic repulsive pressure between clay particles of the same purple soil in our study influenced soil aggregate breakdown, and found that, after aggregate breakdown, the small particles released (separate and micro-aggregates) with a diameter $<2 \mu \mathrm{m}$ exponentially increased with the increase of electrostatic repulsive pressure, indicating that the surface properties of clay particles strongly influence soil aggregate stability. Moreover, Li et al. (2013) further studied the relationship between transport ability of soil particles during rainfall and the surface potential of soil particles for the same purple soil in this study. They found that, with the increase of surface potential, the intensity of particle transport during rainfall sharply increased, implying that the electrostatic repulsive pressure determined the intensity of soil transport in natural systems.

In conclusion, the surface properties of various particlesize fractions, especially the electrochemical properties at the particle surface for the smaller soil particles, would strongly influence clay particle interactions in natural soil, and thus influence soil aggregate stability and soil erosion. By virtue of the fact that most of the nutrients and contaminants are transported to the earth surface water via small soil particles, especially the colloidal- and nano-size particles (Sumner, 1999; Yang et al., 2009), understanding the size distributions of surface properties for soil particles, especially for colloidalsized soil particles, would be an important issue in soil and water environments.

\section{Conclusions}

The size distribution of surface properties of soil particles is closely related to soil particle transport during rainfall, thus this is an important issue in soil and water environments.
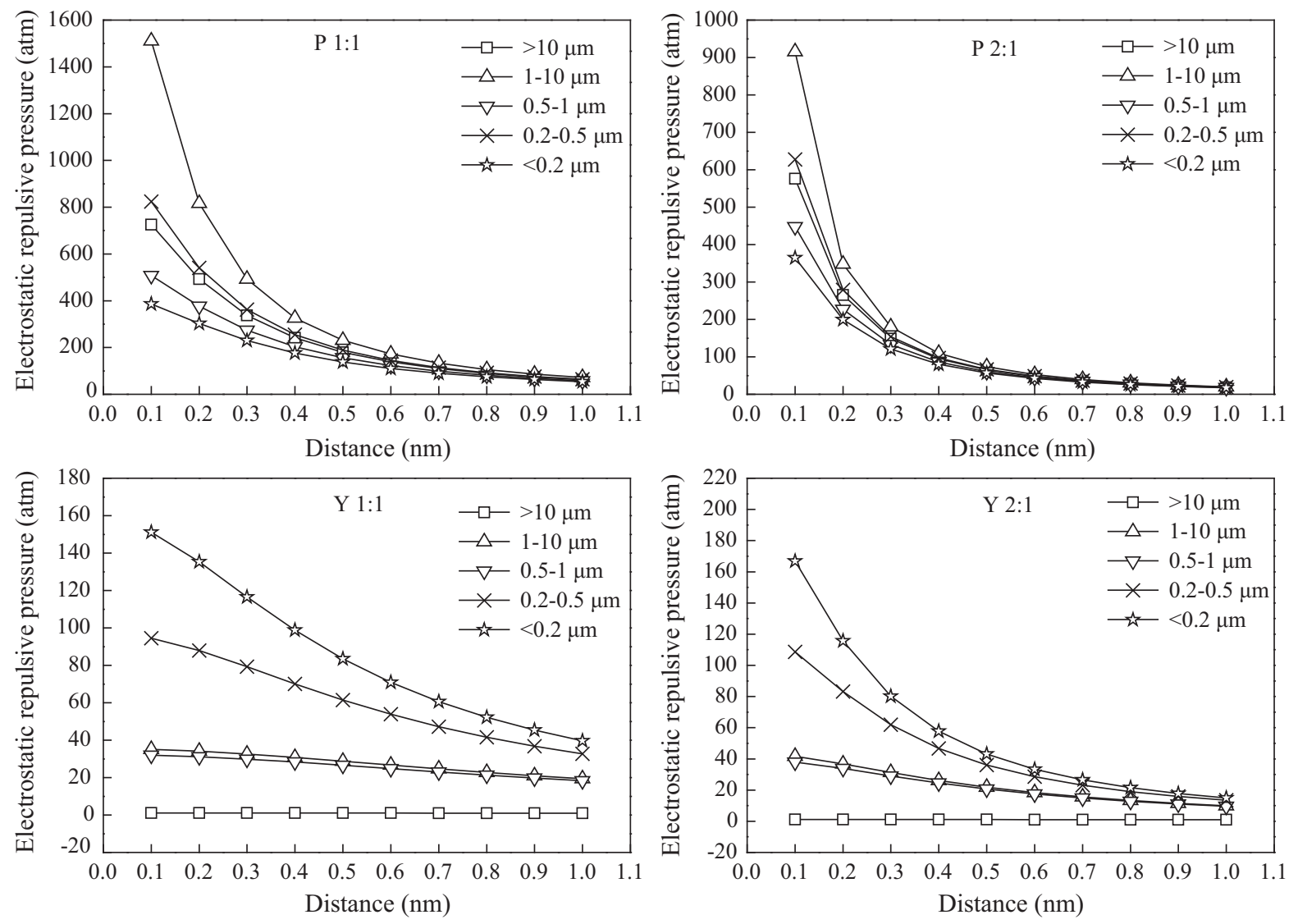

Fig. 3 - Electrostatic repulsive pressure of soil particles within different size ranges under different distances between two adjacent particle surfaces in a single 1:1 or 2:1 electrolyte solution. P: purple soil, Y: yellow soil. 
This study was conducted to clarify the surface properties and soil mineralogy of various particle-size fractions (i.e., >10, 1-10, $0.5-1,0.2-0.5$ and $<0.2 \mu \mathrm{m})$ for two typical soil species in Southwestern China. Up to $85 \%$ of the surface charges and specific surface area came from colloidal-sized particles in the size range $<1 \mu \mathrm{m}$, and the smallest particles $<0.2 \mu \mathrm{m}$ contributed the largest proportion ( $50 \%)$ to these surface properties, implying that colloidal-sized soil particles, especially the smallest soil nanoparticles, played a decisive role in overall soil surface properties. Additionally, the variation of the contents and proportions of soil secondary clay minerals in various particle-size fractions for the two soils were consistent with the change trends of their surface properties, indicating that surface properties of different particle-size fractions depended on their clay mineral compositions.

\section{Acknowledgments}

This work was supported by the Major Science and Technology Program for Water Pollution Control and Treatment (No. 2012ZX07104-003), the Natural Science Foundation Project of CQ CSTC (No. CSTC, 2011BA7001) and the National Natural Science Foundation of China (No. 40971146).

\section{R E F E R E N C E S}

Ajmone-Marsan, F., Biasioli, M., Kralj, T., Grčman, H., Davidson, C.M., Hursthouse, A.S., et al., 2008. Metals in particle-size fractions of the soils of five European cities. Environ. Pollut. 152 (1), 73-81.

Bakshi, S., He, Z.L., Harris, W.G., 2014. A new method for separation, characterization, and quantification of natural nanoparticles from soils. J. Nanoparticle Res. 16 (1), 2261.1-2261.11.

Bower, C.A., Gschwend, F.B., 1952. Ethylene glycol retention by soils as a measure of surface area and interlayer swelling. Soil Sci. Soc. Am. J. 16 (4), 342-345.

Brunekreef, B., Russell, A., 2009. Particulate matter and human health focus issue. Environ. Sci. Technol. 43 (13), 4613-4614.

Calabi-Floody, M., Bendall, J.S., Jara, A.A., Welland, M.E., Theng, B.K.G., Rumpel, C., et al., 2011. Nanoclays from an Andisol: extraction, properties and carbon stabilization. Geoderma 161 (3-4), 159-167.

Cheng, Q.J., Cai, Q.G., Hu, X., 2007. Rain splash erosion and soil crust development of loess soils different in particle-size. Acta Pedol. Sin. 44 (3), 392-396.

Ding, W.Q., Li, Q., Li, H., 2010. Effect of surface charge properties on ion diffusion in soil colloid interface. Acta Pedol. Sin. 47 (5), 896-904.

Dolinar, B., 2012. A simplified method for determining the external specific surface area of non-swelling fine-grained soils. Appl. Clay Sci. 64, 34-37.

Ducker, W.A., Senden, T.J., Pashley, R.M., 1992. Measurement of forces in liquids using a force microscope. Langmuir 8 (7), 1831-1836.

Ersahin, S., Gunal, H., Kutlu, T., Yetgin, B., Coban, S., 2006. Estimating specific surface area and cation exchange capacity in soils using fractal dimension of particle-size distribution. Geoderma 136 (3-4), 588-597.

Fruhstorfer, P., Schneider, R.J., Weil, L., Niessner, R., 1993. Factors influencing the adsorption of atrazine on montmorillonitic and kaolinitic clays. Sci. Total Environ. 138 (1-3), 317-328.
Grolimund, D., Borkovec, M., Barmettler, K., Sticher, H., 1996. Colloid-facilitated transport of strongly sorbing contaminants in natural porous media: a laboratory column study. Environ. Sci. Technol. 30 (10), 3118-3123.

Guber, A.K., Rawls, W.J., Shein, E.V., Pachepsky, Y.A., 2003. Effect of soil aggregate size distribution on water retention. Soil Sci. 168 (4), 223-233.

Guo, W., Shi, Z.H., Chen, L.D., Li, Z.X., Yan, F.L., Cai, C.F., 2007. Effects of topsoil aggregate size on runoff and erosion at hillslope in red soils. Acta Ecol. Sin. 27 (6), 2516-2522.

Henderson, J.J., Crum, J.R., Wolff, T.F., Rogers, J.N.I., 2005. Effects of particle size distribution and water content at compaction on saturated hydraulic conductivity and strength of high sand content root zone materials. Soil Sci. 170 (5), 315-324.

Hillel, D., 1998. Environmental Soil Physics: Fundamentals, Applications, and Environmental Considerations. Academic Press.

Hou, J., Li, H., Zhu, H.L., Wu, L.S., 2009. Determination of clay surface potential: a more reliable approach. Soil Sci. Soc. Am. J. 73 (5), 1658-1663.

House, W.A., Farr, I.S., 1989. Adsorption of sulphonates from detergent mixtures on potassium kaolinite. Colloids Surf. 40, 167-180.

Hu, X.R., Lu, G.L., Yang, Y., 2000. Determination of cation-exchange capacity in clay $\left[\mathrm{Co}\left(\mathrm{NH}_{3}\right)_{6}\right]^{3+}$ exchange method. Chin. J. Anal. Chem. 28, 1402-1405.

Hu, F.N., Xu, C.Y., Li, H., Li, S., Yu, Z.H., Li, Y., et al., 2015. Particles interaction forces and their effects on soil aggregates breakdown. Soil Tillage Res. 147, 1-9. http://dx.doi.org/10.1016/j.still.2014.11. 006.

Huang, C.Y., 2000. Agrology. China Agriculture Press, Beijing, pp. 72-73.

Jenny, H., Reitemeier, R.F., 1934. Ionic exchange in relation to the stability of colloidal systems. J. Phys. Chem. 39 (5), 593-604.

Jia, M.Y., Li, H., Zhu, H.L., Tian, R., Gao, X.D., 2013. An approach for the critical coagulation concentration estimation of polydisperse colloidal suspension of soul and humus. J. Soils Sediments 13 (2), 325-335.

Jiang, X.J., Ma, Y.Y., Yuan, J.J., Wright, A.L., Li, H., 2011. Soil particle surface electrochemical property effects on abundance of ammonia-oxidizing bacteria and ammonia-oxidizing archaea, $\mathrm{NH}_{4}^{+}$activity, and net nitrification in an acid soil. Soil Biol. Biochem. 43 (11), 2215-2221.

Kiem, R., Kögel-Knabner, I., 2002. Refractory organic carbon in particle-size fractions of arable soils II: organic carbon in relation to mineral surface area and iron oxides in fractions $<6 \mu \mathrm{m}$. Org. Geochem. 33 (12), 1699-1713.

Li, G.L., Pang, X.M., 2014. Difference in organic carbon contents and distributions in particle-size fractions between soil and sediment on the Southern Loess Plateau, China. J. Mt. Sci. 11 (3), 717-726.

Li, H., Peng, X.H., Wu, L.S., Jia, M.Y., Zhu, H.L., 2009. Surface potential dependence of the Hamaker constant. J. Phys. Chem. C 113 (11), 4419-4425.

Li, H., Li, R., Zhu, H.L., Wu, L.S., 2010a. Influence of electrostatic field from soil particle surfaces on ion adsorption-diffusion. Soil Sci. Soc. Am. J. 74 (4), 1129-1138.

Li, W.Y., Xu, J.M., Huang, P.M., 2010b. Molecular Environmental Soil Science at the Interfaces in the Earth's Critical Zone, Section 4: Extraction of Nanoparticles from Argosols and Ferrosols. Springer, Berlin Heidelberg, pp. 275-278.

Li, H., Hou, J., Liu, X.M., Li, R., Zhu, H.L., Wu, L.S., 2011. Combined determination of specific surface area and surface charge properties of charged particles from a single experiment. Soil Sci. Soc. Am. J. 75 (6), 2128-2135.

Li, W., He, Y., Wu, J., Xu, J., 2012. Extraction and characterization of natural soil nanoparticles from Chinese soils. Eur. J. Soil Sci. 63 (5), 754-761. 
Li, S., Li, H., Xu, C.Y., Huang, X.R., Xie, D.T., Ni, J.P., 2013. Particle interaction forces induce soil particle transport during rainfall. Soil Sci. Soc. Am. J. 77 (5), 1563-1571.

Liu, X.M., Hou, J., Li, R., Li, H., 2010. The iterative method for the direct determination of ion concentration by ion-selective electrodes. J. Southwest Univ. National. (Nat. Sci. Ed.) 32 (11), 124-129.

Lu, R.K., 2000. Analytical Methods for Soil and Agricultural Chemistry. Agricultural Science and Technology Press, Beijing.

Luo, X.S., Yu, S., Li, X.D., 2011. Distribution, availability, and sources of trace metals in different particle size fractions of urban soils in Hong Kong: implications for assessing the risk to human health. Environ. Pollut. 159 (5), 1317-1326.

Madrid, F., Biasioli, M., Ajmone-Marsan, F., 2008. Availability and bioaccessibility of metals in fine particles of some urban soils. Arch. Environ. Contam. Toxicol. 55 (1), 21-32.

McCarthy, J.F., Zachara, J.M., 1989. Subsurface transport of contaminants. Environ. Sci. Technol. 23 (5), 496-502.

Petersen, L.W., Moldrup, P., Jacobsen, O.H., Rolston, D.E., 1996. Relations between specific surface area and soil physical and chemical properties. Soil Sci. 161 (1), 9-21.

Ryan, J.N., Elimelech, M., 1996. Colloid mobilization and transport in groundwater. Colloids Surf. A Physicochem. Eng. Asp. 107, 1-56.

Saggar, S., Parshotam, A., Hedley, C., Salt, G., 1999. ${ }^{14}$ C-labelled glucose turnover in New Zealand soils. Soil Biol. Biochem. 31 (14), 2025-2037.

Schmidt, C.W., 2010. Lead in air: adjusting to a new standard. Environ. Health Perspect. 118 (2), A76-A79.

Six, J., Conant, R.T., Paul, E.A., Paustian, K., 2002. Stabilization mechanisms of soil organic matter: implications for C-saturation of soils. Plant Soil 241 (2), 155-176.

Sumner, M.E., 1999. Handbook of Soil Science. CRC Press, Boca Raton.

Tian, R., Li, H., Zhu, H.L., Liu, X.M., Gao, X.D., 2013. Ca and Cu induced aggregation of variably charged soil particles: a comparative study. Soil Sci. Soc. Am. J. 77 (3), 774-781.

Tian, R., Yang, G., Li, H., Gao, X.D., Liu, X.M., Zhu, H.L., et al., 2014. Activation energies of colloidal particle aggregation: towards a quantitative characterization of specific ion effects. Phys. Chem. Chem. Phys. 16 (19), 8828-8836.
Tsao, T., Chen, Y.M., Sheu, H., Tzou, Y., Chou, Y., Wang, M.K., 2013. Separation and identification of soil nanoparticles by conventional and synchrotron X-ray diffraction. Appl. Clay Sci. $85,1-7$.

Wang, P., Keller, A.A., 2008. Particle-size dependent sorption and desorption of pesticides within a water-soil-nonionic surfactant system. Environ. Sci. Technol. 42 (9), 3381-3387.

Wang, X.-S., Qin, Y., Chen, Y.-K., 2006. Heavy meals in urban roadside soils, part 1: effect of particle size fractions on heavy metals partitioning. Environ. Geol. 50 (7), 1061-1066.

Wilkinson, K.J., Lead, J.R., 2007. Environmental Colloids and Particles: Behaviour, Separation and Characterisation. John Wiley and Sons, New York.

Wischmeier, W.H., Mannering, J.V., 1969. Relation of soil properties to its erodibility. Soil Sci. Soc. Am. J. 33 (1), 131-137.

Wösten, J.H.M., Pachepsky, Y.A., Rawls, W.J., 2001. Pedotransfer functions: bridging the gap between available basic soil data and missing soil hydraulic characteristics. J. Hydrol. 251 (3), 123-150.

Wu, H.Y., Jiang, D.H., Cai, P., Rong, X.M., Dai, K., Liang, W., et al., 2012. Adsorption of pseudomonas putida on soil particle size fractions: effects of solution chemistry and organic matter. J. Soils Sediments 12 (2), 143-149.

Xiong, Y., Chen, J., Zhang, J., 1985. Soil Colloid (2): Methods for Soil Colloid Research. Science Press, Beijing.

Yang, J.H., Wang, C.L., Dai, H.L., 2008. Soil Agrochemical Analysis and Environmental Monitoring. China Earth Press, Beijing.

Yang, J.L., Zhang, G.L., Shi, X.Z., Wang, H.J., Cao, Z.H., Ritsema, C.J., 2009. Dynamic changes of nitrogen and phosphorus losses in ephemeral runoff processes by typical storm events in Sichuan basin, Southwest China. Soil Tillage Res. 105 (2), 292-299.

Yonekura, Y., Ohta, S., Kiyono, Y., Aksa, D., Morisada, K., Tanaka, N., et al., 2013. Soil organic matter dynamics in density and particle-size fractions following destruction of tropical rainforest and the subsequent establishment of imperata grassland in Indonesian Borneo using stable carbon isotopes. Plant Soil 372 (1-2), 683-699.

Yu, T.R., 1976. Edaphic Electro-chemical Properties and Organon (Recension). Science Press, Beijing, pp. 68-85. 